\title{
Synoptic and seasonal variations of the ice-ocean circulation in the Arctic: a numerical study
}

\author{
Alex WARn-VARnas \\ SACLANT Research Center, La Spezia, Italy \\ RICHARD ALLARD \\ Berkeley Research Associates, Springfield, VA, U.S.A. \\ Steve Piacsek \\ Navy Ocean and Atmospheric Research Laboratory, Stennis Space Center, MA, U.S.A.
}

\begin{abstract}
The circulations of the Arctic ice cover and ocean are investigated using a coupled ice-ocean model. The coupling is strong and two-way for synoptic time scales, but is limited on seasonal time scales: the geostrophic ocean currents are not changed by the computed heat and salt fluxes. The ice-drift motion, Ekman transports and the wind-driven part of the barotropic circulation are examined for the months of February and August 1986, representing different atmospheric forcing, icethickness and ice-strength regimes. Initial examination of the results revealed no significant seasonal dependence of ice-drift response on the synoptic time scale, other than larger velocities with larger wind stresses. Daily maximum ice-drift velocities range from $20-40 \mathrm{~cm} \mathrm{~s}^{-1}$ in February, and $15-30 \mathrm{~cm} \mathrm{~s}^{-1}$ in August. The corresponding mean monthly maximum drifts were 11 and $9 \mathrm{~cm}$, respectively. The drag associated with the geostrophic currents plays a much bigger role in the summer because of the lighter atmospheric stresses. The well-known reversal of the normally clockwise Beaufort Gyre to a cyclonic system in August takes place in a few days and lasts well into September. In February, the Beaufort Gyre varies between a large, clockwise system covering all the Canadian Basin to a small, tight gyre centered over the southern Beaufort Sea, without any hint of reversal or disappearance. Large areas of strong divergence were found in the Ekman transport patterns, as well as the icedivergence fields, indicating areas where ice thinning, openings and new ice formation might occur. In August this occurred in the Chukchi Sea, and in February just north of Novaya Zemlya.
\end{abstract}

\section{INTRODUCTION}

It is well known that the Arctic ice cover acts as an insulator or shield against both heat and momentum transfer from the atmosphere to the ocean. This interesting geophysical process has been the subject of many studies. In particular, Lemke (1987), Mellor and Kantha (1989) and Bjork (1989) have used one-dimensional models to study the details of the heat and momentum transfer processes, as well as the maintenance of the mean vertical structure of the Arctic Basin. There have also been three-dimensional (3-D) coupled ice-ocean modeling studies by Semtner (1987) and Hibler and Bryan (1987), both using prognostic ice models but the latter using a diagnostic ocean model. In each of the 3-D studies, however, the turbulent mixed layer has been parameterized in a very simple manner, assuming a constant layerdepth to the first sub-surface grid-point. The current study has aimed to improve on this aspect of Arctic modeling by introducing an active, second-order closure turbulent mixed-layer model under the ice that is driven by $12 \mathrm{~h}$ general circulation model (GCM)-derived atmospheric momentum and heat fluxes. Although this study involved a complete treatment of the thermodynamics and hydrodynamics of the 3-D ice-ocean system over the year 1986, the focus of the present paper will be on momentum processes and circulation.

The generation of oceanic circulation by the curl of the overlying wind stress is a non-trivial problem in an ocean with topography, and has been the subject of many theoretical and numerical studies. The presence of an ice cover presents an additional complication and gives rise to several questions: how much of the wind curl is transmitted to produce circulation in the ocean; how much stress is available to produce mixing and Ekman currents in the surface layers under the ice, and what is the 
drag experienced by the water due to ice-form drag and turbulent viscosity? Answers to the last two questions have been addressed at length by McPhee (1982, 1990), but answers to the first question are still incomplete, if not lacking, especially on the observational side.

In the upper ocean region (which, in the winter, includes depths down to $500 \mathrm{~m}$ or more), the oceanic velocity is a superposition of the Ekman, inertial and geostrophic velocities. On seasonal time scales, the geostrophic velocity is dominant, but there can be important net contributions to the transports from the Ekman drifts as well, especially during periods of very high winds, which are common in winter and spring periods.

The reverse question, therefore, is also of great interest: to what extent, and on what time scale, do the geostrophic currents modify the ice motion?

\section{MODELING APPROACH}

The coupled ice-ocean model used in these studies contains the Hibler (1979) ice model and a 3-D ocean model that consists of a turbulent mixed-layer model and an inverse geostrophic model. Coupling between the three models is achieved as follows: the ice is coupled to the ocean through flux boundary conditions (including heat, salt and momentum); the mixed layer, in turn, is coupled one-way to a climatological background ocean, receiving advection velocities from a geostrophic inverse model. There is no direct feedback from the computed temperature and salinity changes to the geostrophic currents; i.e. pressure is determined solely from the seasonally-evolving, predetermined climatological density field. The computed Ekman drift and Ekman divergence, however, also contribute horizontal and vertical advection velocities, respectively, to the mixed-layer model.

In particular, on the thermodynamic side, the ocean model calculates the mixed-layer temperature, freezing temperature and oceanic heat flux for the ice model, whereas the ice model determined the stress between the ice and the water and the salinity flux under the ice cover. The Hibler ice code was modified to utilize the mixedlayer temperatures, freezing temperatures and oceanic heat fluxes calculated in the ocean model. The heat budget routine includes the seven-level thickness distribution after Walsh and others (1985).

On the momentum side, the ocean contributes a velocity to the ice-water drag that is the sum of the winddriven Ekman and geostrophic velocities. In turn, the ice momentum equations furnish ice velocities that enter into the ice-water drag force. Since a full turbulent mixed-layer model is used, we employ the ice-water drag rather than the modified wind stress (wind stress minus internal ice stress) as the upper boundary conditions on the ocean (Svensson and Omstedt, 1990). In open water regions, the atmospheric fluxes are used directly for the upper boundary conditions. If a grid cell is ice-covered, the wind stress and the heat fluxes are applied to the ice first, and then the ice-water drag is computed to drive the ocean.

Some additional model particulars will now be described. To simulate the evolution of the mixed layer under the ice and, in general, the thermodynamic changes in the ocean, we have decided to use the TOPS (Thermodynamic Ocean Prediction System) model that has been operational at FNOC (Fleet Numerical Ocean Central) in Monterey, California for several years (Clancy and Pollak, 1983). For this study, the model has been modified to extend to the ocean bottom. The TOPS model employs the Mellor and Yamada (1974) Level-2.5 turbulence-closure method to parameterize the vertical eddy fluxes of temperature, salinity and momentum.

A weak three-year relaxation is imposed on the temperature and salinity fields below $50 \mathrm{~m}$ to prevent the solutions from straying too far from climatology on long model integrations. Our tests with lower or zero values of this constant produced no significant differences in either ice thickness or concentration, and none on the synoptic or monthly time scales (see also Hibler and Bryan, 1987).

The geostrophic velocity at all levels of the ocean is calculated with a beta-spiral type inverse method of Peggion (1988), utilizing seasonal density fields derived from the Levitus (1982) climatological T and S fields. The model assumes the usual hydrostatic and geostrophic approximations, and additional constraints are imposed on the density field due to mass conservation and the topography (see Olbers and others, 1985). The resulting linear equations, fitting all constraints to the data, are solved through a minimization procedure. The computed geostrophic currents are then interpolated to monthly values.

The entire coupled ice-ocean model is defined at equal grid intervals of $127 \mathrm{~km}$ on a polar-stereographic projection, with a total horizontal resolution of $47 \times 25$ grid points. The vertical grids of the TOPS and the inverse models coincide, containing 17 levels in a stretched configuration, with a resolution that places nine points in the first $100 \mathrm{~m}$ and varies from $5 \mathrm{~m}$ near the surface to several hundred meters near the bottom. The resolution is designed to track variations in the mixed layer, rather than track variations of the bottom topography. This grid also corresponds to the grid used by the PIPS (Polar Ice Prediction System) of the Navy in a daily operational setting (Preller, 1985).

In summary, the ice and the upper ocean are represented prognostically, and the interior ocean diagnostically.

\section{MODEL INITIALIZATION AND FORCING}

The Levitus (1982) winter climatology is used to initialize the temperature and salinity fields in the ocean model to a depth of $1500 \mathrm{~m}$, and the annual climatology is used to set values below that depth. The initialization of the ice cover is accomplished by doing a 3-year spin-up of an ice-only model (but using the 1986 fluxes), and then using the resultant ice cover and circulation on the last day of year 3 as the initial ice field on 1 January 1986 of the ice-ocean model, i.e. the first day of simulation year one with the coupled model.

The model was forced by $12 \mathrm{~h}$ atmospheric fluxes derived from the 1986 NOGAPS global-analyzed fields of FNOC. The model domain and the horizontal grid structure are illustrated in Figure 1, and the topography with the corresponding resolution in Figure 2. Note that 


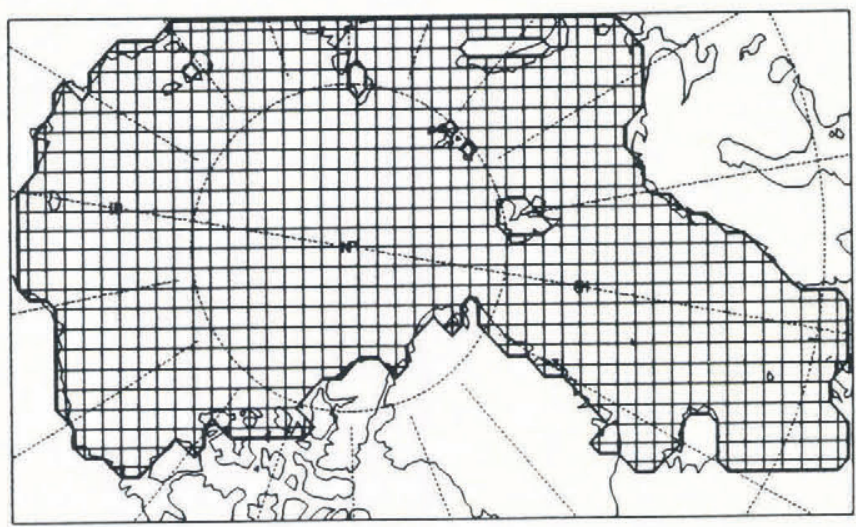

Fig. 1. The basin geometry and horizontal grid structure used in the simulations.

\section{BOTTOM TOPOGRAPHY (METERS)}

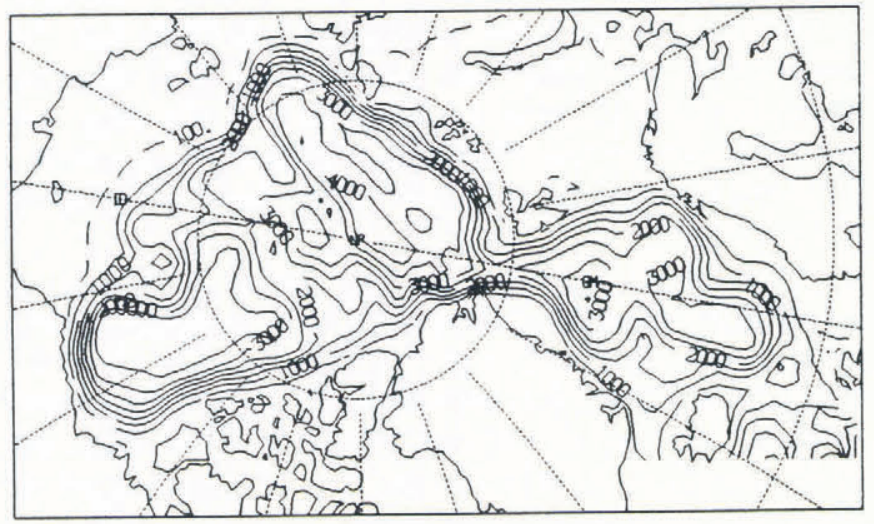

Fig. 2. The topography of the Arctic-Greenland Sea basin with a $127 \mathrm{~km}$ resolution.

only the major ocean basins and ridges are resolved with this resolution.

The model essentially reaches statistical equilibrium after the fourth year of simulation, in the sense that in all aspects the model results during simulation years four and five evolve almost identically. Thus, the results are analyzed for the fifth year.

\section{MODEL RESULTS AND ANALYSIS}

The principal aims of this paper were to study the momentum transfer processes and coupled ice-ocean response to time-dependent winds on the synoptic and seasonal time scales. The accompanying model results on ice thickness, ice extent and the thermohaline structure are being published elsewhere (Piacsek and others, 1990). Since the thickness and compactness of the ice cover vary greatly between seasons, a specific point of interest was the seasonal dependence of the momentum transfer and transient response. Such a study may obtain, indirectly, an insight into the role of the ice cover in momentum transfer between air and water. Another question concerned the role of the geotrophic ocean currents.
They form a very stable drag force compared to the highly variable wind stress so that, on the monthly and certainly the seasonal time scale, their effect should be noticeable if not pronounced.

The results will be grouped according to the following themes: (a) seasonal variations of the ice and water circulation, (b) synoptic evolution of the circulation, and (c) effect of the ice cover on generating water motions. In this short paper we cannot give an exhaustive treatment and answers to all the above questions, but will try to highlight each point by the most illustrative examples.

\section{Seasonal variations of the circulation}

Before we begin a detailed look at synoptic responses and variations that took place in the months of March and August 1986, we will review the corresponding average monthly circulations in order to place the synoptic pictures in a more familiar frame of reference.

Figures 3 and 4 display the wind-velocity and the icemotion fields for the months of February and August 1986. We use the geostrophic wind-velocity fields at $20 \mathrm{~m}$ height instead of the stress fields because they give much better details of the circulation in areas of weak winds, as the stress has a quadratic dependence on the wind speed. Keeping the maximum arrow lengths in the respective figures reasonable (i.e. non-overlapping and covering no more than three neighboring grid boxes) left us sometimes with arrows too small to be discerned clearly over large areas of the domain when the stress was plotted.

Overall, the February winds over the Arctic are composed of a large anticyclonic gyre over the Canadian Basin and a strong, wide "transpolar jet" over the Eurasian Basin, moving from east-central Siberia toward Norway. Note the highs over the Beaufort Sea, Baffin Island and the southern Norwegian Sea, and the large low pressure area about $20^{\circ}$ east of Novaya Zemlya. The corresponding ice motion (with average maximum of $11 \mathrm{~cm} \mathrm{~s}^{-1}$ ) reflects the overall wind pattern quite accurately: the usual anticyclonic Beaufort Gyre occupying a slightly larger area than the overlying high pressure winds, and a wide transpolar flow paralleling closely the atmospheric transpolar pattern over almost the same domain.

The atmosphere in August is characterized by two high pressure regions, a strong one over the Greenland Sea and a weak one over the Beaufort Sea, and a very large and intense cyclonic low over the whole Canadian Basin. Between this low and the Greenland Sea high there runs a well-formed "reverse polar jet" from an area east of Greenland toward eastern Siberia. The corresponding ice motion consists of a strong cyclonic gyre over the central Arctic and an anticyclonic flow in the southern Beaufort Sea. However, note that, whereas the areas occupied by the large cyclonic wind and ice patterns are about the same, the centers of the gyres are separated considerably and the streamlines do not coincide as well as they do in February. There is considerable eastward movement of ice under the western part of the (here southward flowing) reverse polar jet, and considerable eastward ice movement across the northerly winds just north of Greenland.

We also note that the rather well-formed anticyclonic ice motion (a remnant of the Beaufort Gyre?) is located west of the weak high centered at the westeren end of the 


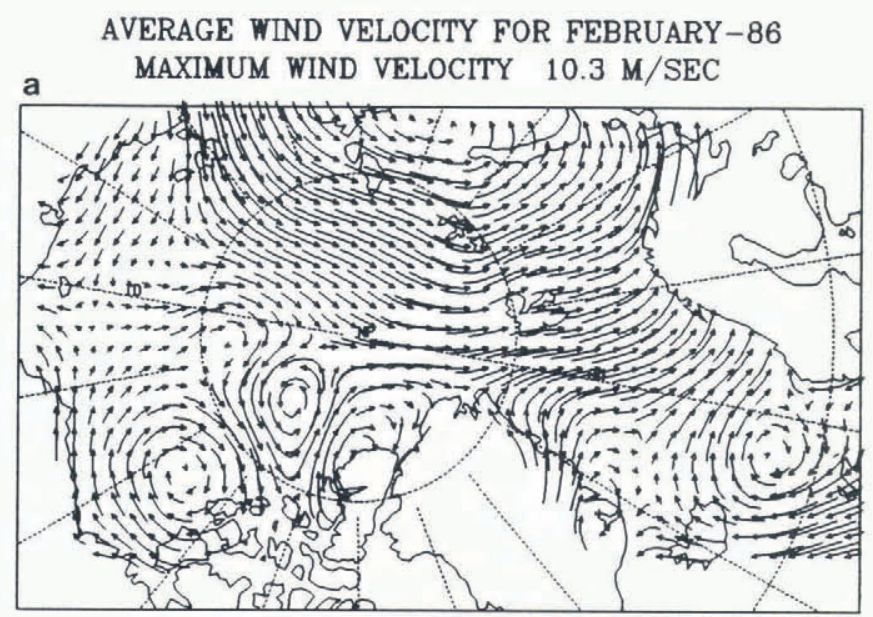

ICE VELOCITIES FOR FEBRUARY -86
MAXIMUM ICE VELOCITY

b

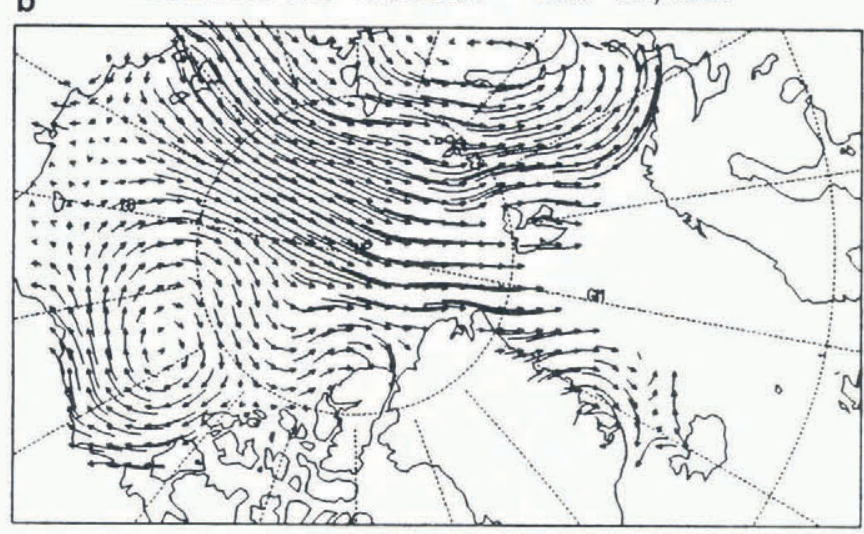

GEOSTROPHIC SURFACE CURRENTS FOR FEBRUARY c

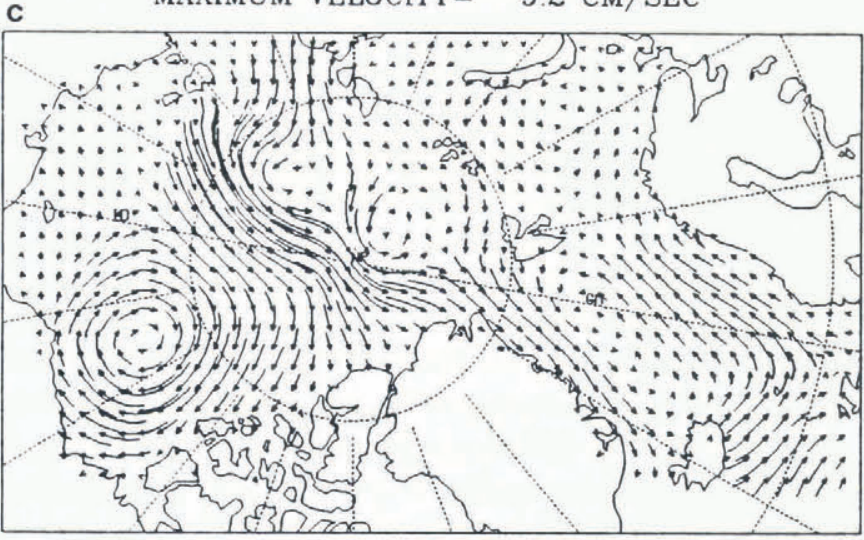

AVERAGE ICE VELOCITIES FOR MARCH-86

d MAXIMUM ICE VELOCITY $15.6 \mathrm{CM} / \mathrm{SEC}$

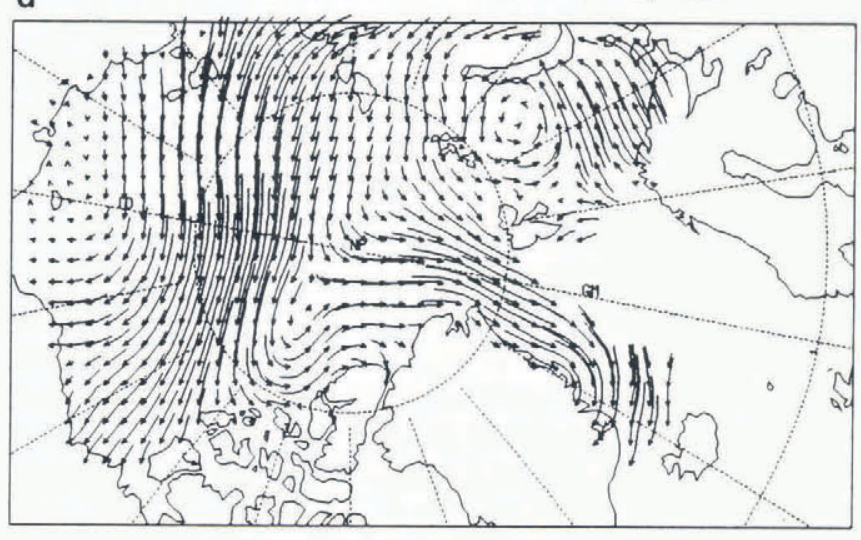

Fig. 3. The geostrophic wind velocity at $20 \mathrm{~m}$ (a), ice-drift motion (b), and geostrophic ocean current (c) for the month of February 1986; ice-drift motion for March 1986 (d).
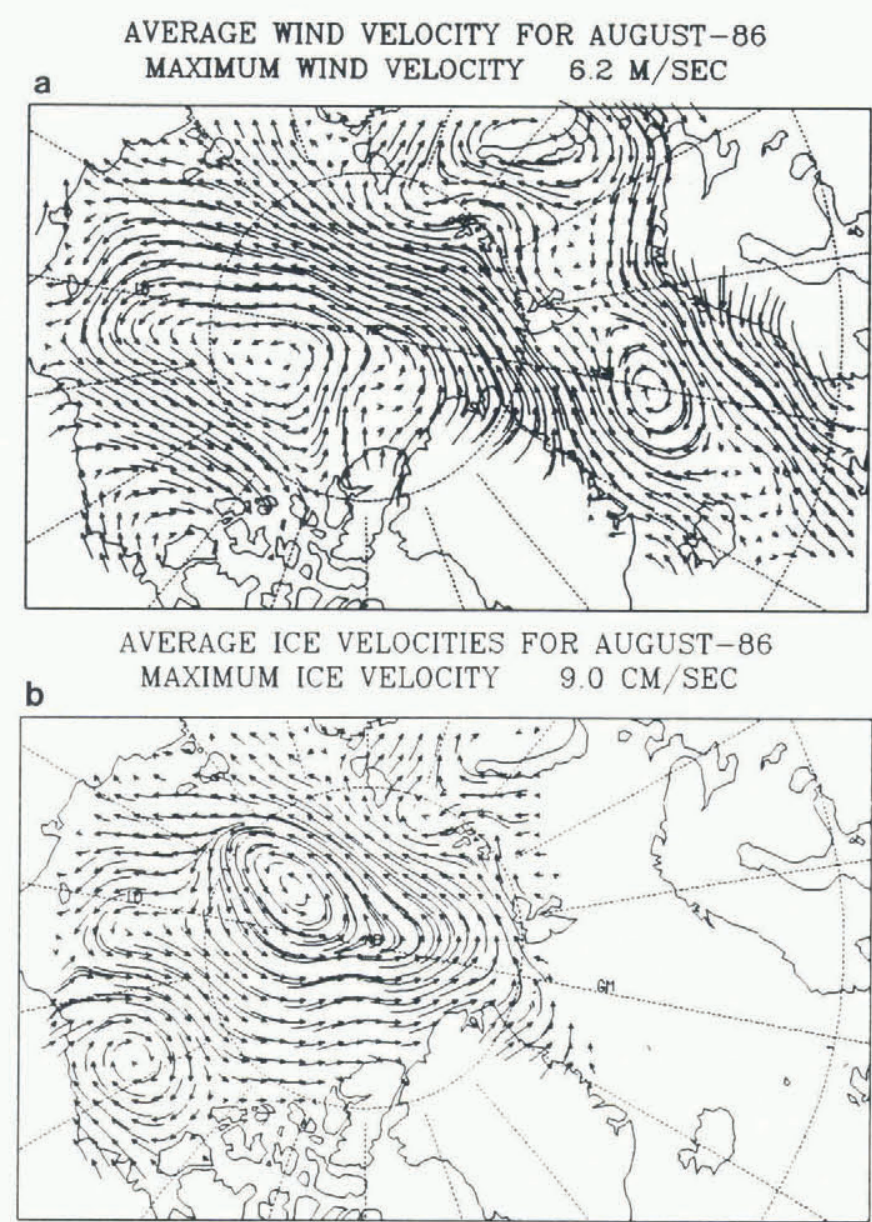

GEOSTROPHIC SURFACE CURRENTS FOR AUGUST MAXIMUM VELOCITY $=9.9 \mathrm{CM} / \mathrm{SEC}$

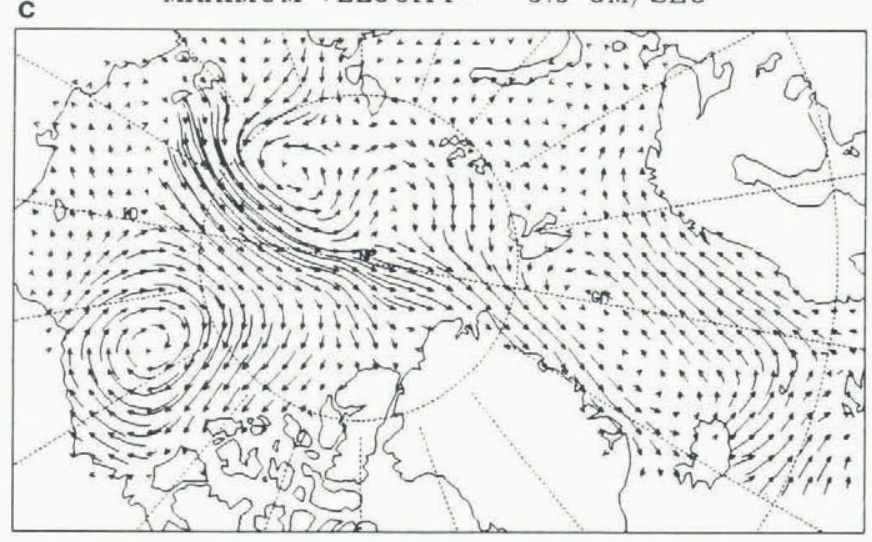

Fig. 4. The geostrophic wind velocity at $20 \mathrm{~m}$ (a), ice-drift motion (b), and geostrophic ocean current (c) for the month of August 1986.

Canadian Arctic Archipelago, and occupies a much larger area than the winds associated with this high. A look at the geostrophic velocity patterns in August (Fig. 4c) would seem to suggest a solution to the discrepancy: strong anticyclonic ocean currents in this region could well supply the missing forcing for this large anticyclonic ice gyre. The same argument could also be applied to the February circulation, where the geotrophic currents (Fig. 3c) seem to reinforce the atmospheric Beaufort Gyre to force the strong anti-cyclonic ice drift. However, a look at the average ice velocities in March (Fig. 3d) serves a warning that the situation can become more complicated. 


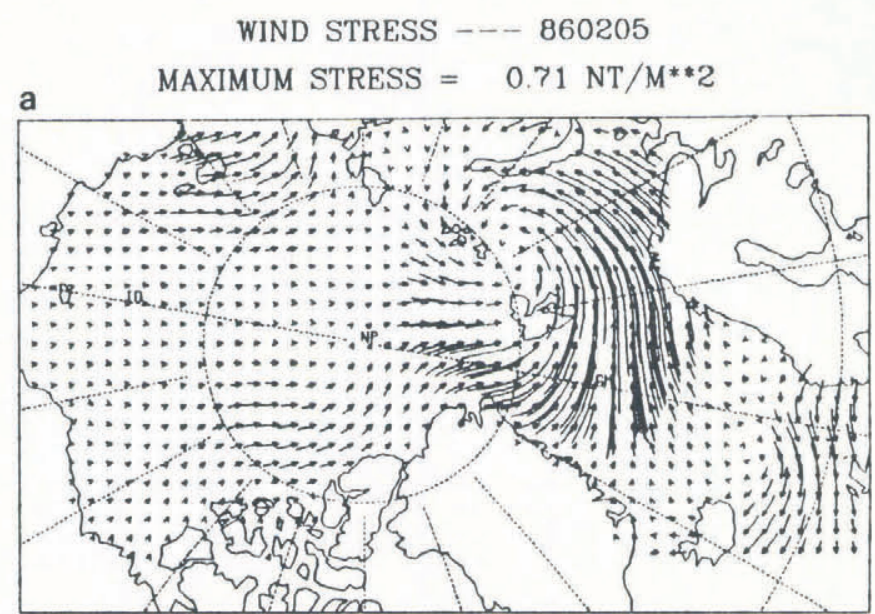

ICE VELOCITIES -- 860205

b MAXIMUM VELOCITY $31.9 \mathrm{cM} / \mathrm{SEC}$

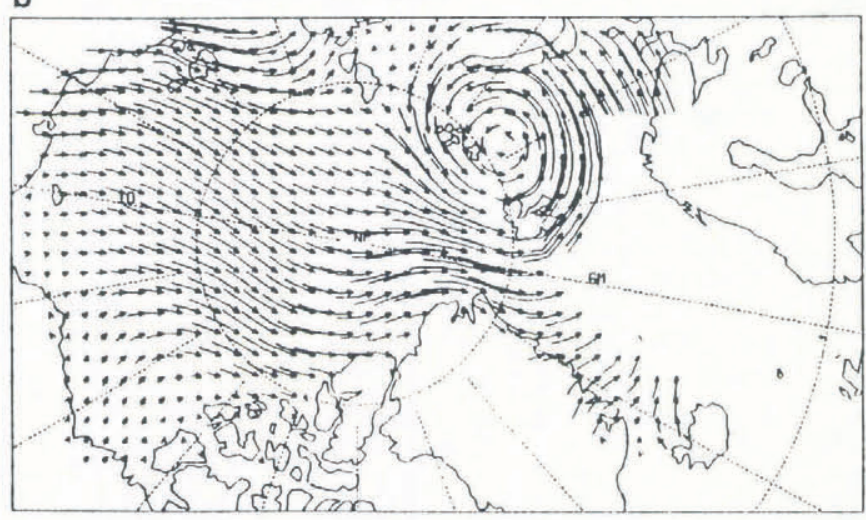

Fig. 5. The wind stress (a) and ice-drift motion (b) for 5 February 1986.

Although the March currents are almost identical to those in February, there seems to be no evidence of an anticyclonic ice motion in this region, implying that the strong March winds (average maximum of $14 \mathrm{~m} \mathrm{~s}^{-1}$ ) in this area dominate the current drag. Since the maximum average winds in August are only about $6 \mathrm{~m} \mathrm{~s}^{-1}$ (and the stress goes quadratic with speed), we would expect the effects of the geostrophic currents to be much stronger in the summer.

\section{Synoptic variations}

The synoptic evolution of the wind patterns and the corresponding ice motions for February 1986 are illustrated in Figures 5-11. A careful inspection of all the daily plots has revealed the presence of five basic patterns which last $3-5 \mathrm{~d}$ on the average, with the 27 February pattern repeating that of 5 February quite closely.

Figure $5(\mathrm{a}, \mathrm{b})$ shows the wind stress and ice-drift velocity for 5 February. The strong low pressure system east of Spitsbergen drives a corresponding strong, cyclonic ice-gyre centered on the same location. A weak, eastwardmoving jet north of Greenland and Canada drives a very wide transpolar ice-drift current, which narrows and intensifies upon reaching the Fram Strait, partly due to the southerly winds of the Spitsbergen low and partly due to the strengthening coastal atmospheric jet.

Three days later on 8 February the situation is
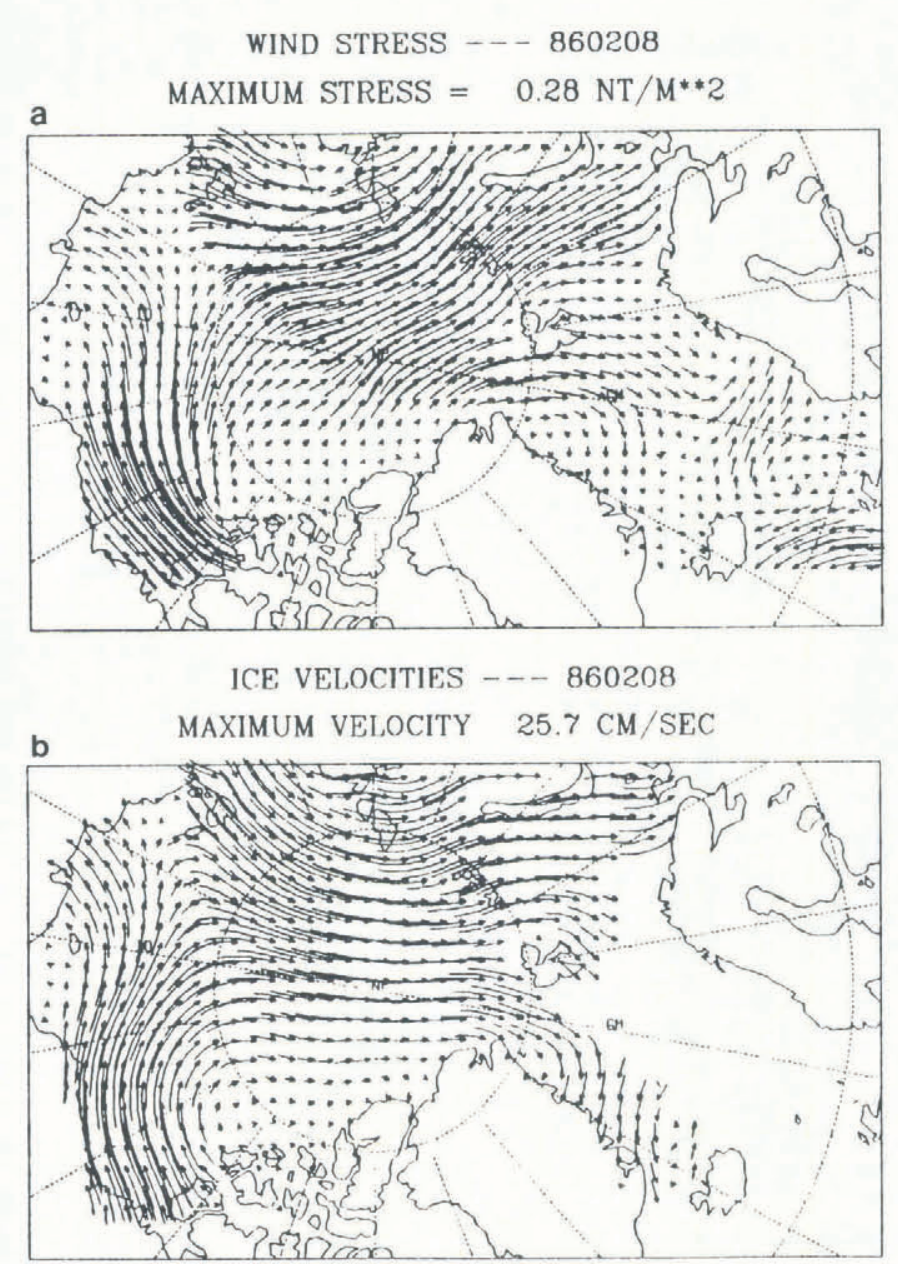

Fig. 6. The wind stress (a) and ice-drift motion (b) for 8 February 1986.

illustrated in Figure 6(a,b). The winds have completely changed: we now have highs north of Canada and northeast of Greenland and a strong low over the Siberian coast (reminiscent of the average winds). These highs and lows drive a strong westerly atmospheric jet over the Beaufort Sea and a wide transpolar jet south along $20^{\circ} \mathrm{E}$ toward the Barents Sea. Whereas the ice motion in the Beaufort Sea closely parallels the winds, it forms a wide transpolar ice drift over the central Arctic which is at a $30^{\circ}$ angle to the right of the wind.

The perennial Beaufort Gyre surfaces on 11 February (not shown). We illustrate the ice-drift situation on 12 February (Fig. 7a), which shows the presence of a dominating anticyclonic gyre over the whole western half of the Arctic Basin and a reverse flow of ice into the Arctic through the Fram Strait. The next day (Fig. 7b) illustrates an ice-drift configuration most efficient for transporting and piling up against the northern shores of Canada and Greenland. It consists of a large anticyclonic (clockwise) gyre over the Canadian half of the Arctic Basin, and an intense gyre just north of the Fram Strait, driving between them a very strong southwesterly drift-current toward these shores. The ice velocity on this day peaks at $37 \mathrm{~cm} \mathrm{~s}^{-1}$ and the maxima tends to occur near the pole.

On 16 February (Fig. 8b) the large Beaufort Gyre has shrunk to a small, tight but very energetic gyre and a strong, well-formed transpolar drift, with a lot of ice 
ICE VELOCITIES - - 860212 MAXIMUM VELOCITY $29.0 \mathrm{CM} / \mathrm{SEC}$

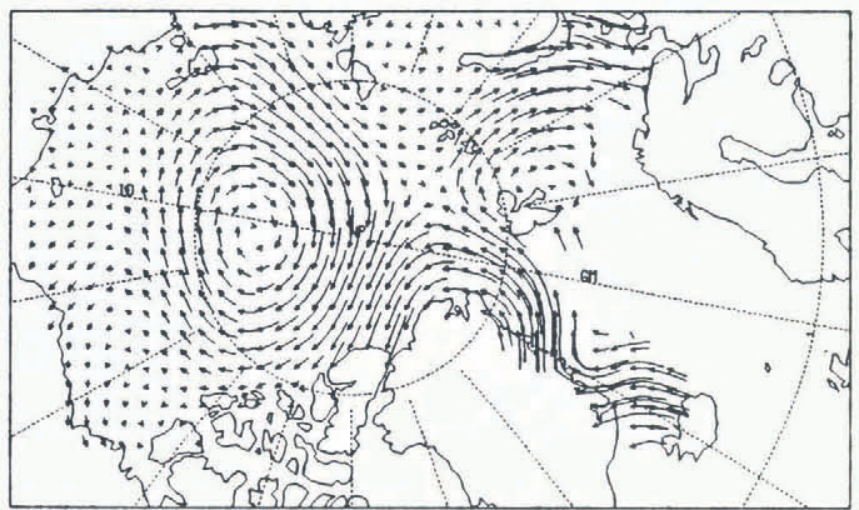

ICE VELOCITIES - - 860213

b MAXIMUM VELOCITY $37.4 \mathrm{CM} / \mathrm{SEC}$

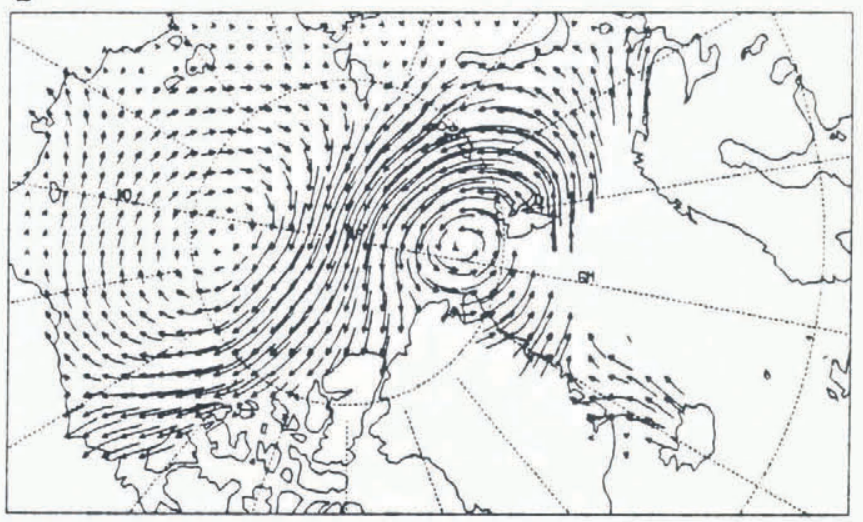

Fig. 7. The ice-drift motion for 12 February (a) and 13 February (b), 1986.

exiting through the Fram Strait and also into the Barents Sea. This ice movement is caused by a peculiar wind pattern (Fig. 8a): a very long high pressure ridge causing winds to form a very wide northwesterly stream that seems to intensify suddenly everywhere as it crosses the $80^{\circ} \mathrm{N}$ latitude circle. On this day the transpolar ice drift is about $40^{\circ}$ to the right of the wind in almost all locations except in the southwest part of the Beaufort Gyre, where the ice drift and wind are almost parallel.

Figures 9 to 11 display the synoptic variations of the winds and circulations in mid-August 1986. Three snapshots of the flow are presented four days apart, i.e. for the days 9, 13 and 17 August, respectively. The atmosphere on 9 August is characterized by a low south of Iceland, a high over Franz Josef Land and a weak low over Siberia. By 13 February a high develops south of Spitsbergen, and the low intensifies off Siberia and moves toward the Bering Strait. By 17 February, the Siberian low has grown tremendously and covers the larger part of the Canadian Basin.

The corresponding ice motion changes from a highly deformed, jet stream-like wave on 9 February to a giant cyclonic gyre occupying the most part of the Canadian Basin, driven evidently by the large low pressure cyclone. This well-established reversal of the normally clockwise Beaufort Gyre has been simulated and discussed by Preller and Posey (1989). The strong transpolar drift, a common
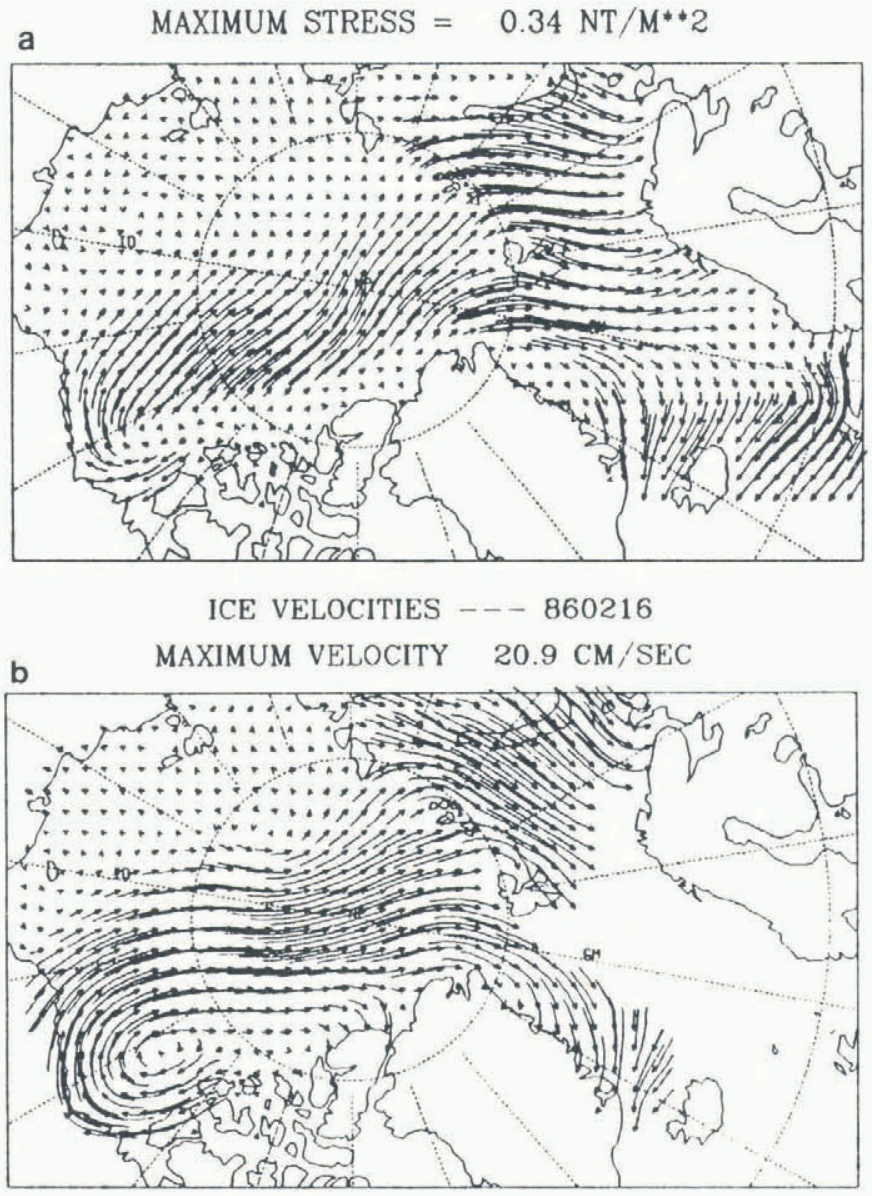

Fig. 8. The wind stress (a) and ice-drift motion (b) for 16 February 1986.

feature of the ice motion, is mostly evident only on 13 February; however, it is also present on 9 February, but with an orientation $90^{\circ}$ to the usual Bering-Fram strait line, moving rather from Greenland toward Siberia.

\section{Ekman transport}

The Ekman transports corresponding to the wind-stress fields of 5 February and 17 August are depicted in Figure 12. These transports are computed between the surface and the $50 \mathrm{~m}$ depth level; the figures show the average velocity in this layer. On 5 February (Fig. 12a) we note a series of alternating diverging and converging regions over the Canadian Basin, and a very intense divergence region under the strong atmospheric low near Novaya Zemlya. The situation on 17 August (Fig. 12b) is dominated by a huge divergence under the large cyclonic gyre, and a strong offshore transport west of Norway, about $45^{\circ}$ to the right of the southerly wind stream paralleling the Norwegian coast. The maximum velocities are about 8.6 and $5.6 \mathrm{~cm} \mathrm{~s}^{-1}$, respectively. Although not illustrated in this paper, areas of strong divergence in the Ekman transport tend to be indicative of areas of ice divergence. This is particularly true for the case of the large cyclonic gyre in the Canadian Basin, indicating a thinning of the ice cover. In some cases this can lead to areas of ice opening as well as new ice formation. 
WIND STRESS --- 860809

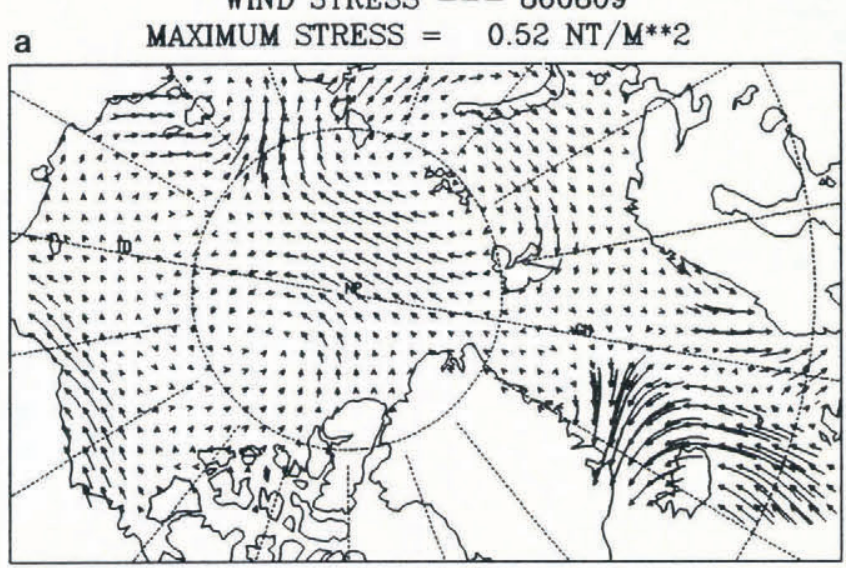

ICE VELOCITIES - - 860809

b MAXIMUM VELOCITY $17.9 \mathrm{cM} / \mathrm{SEC}$

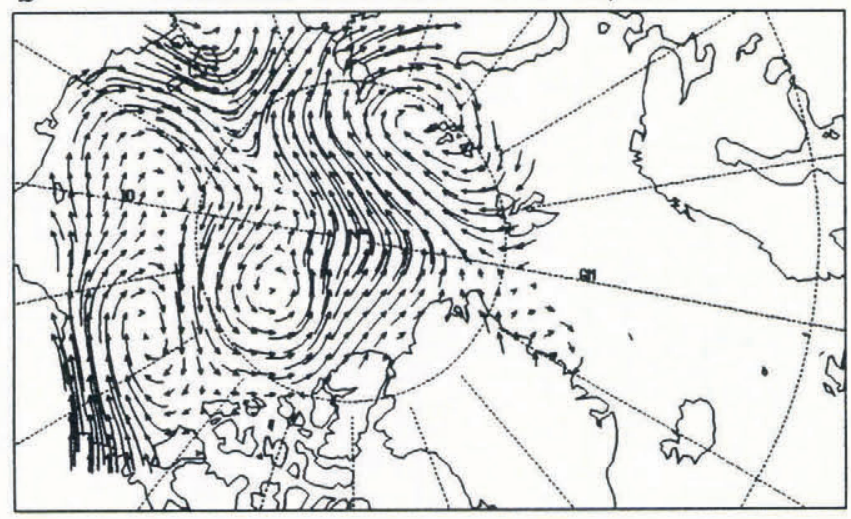

Fig. 9. The wind stress (a) and ice-drift motion (b) for 9 August 1986.

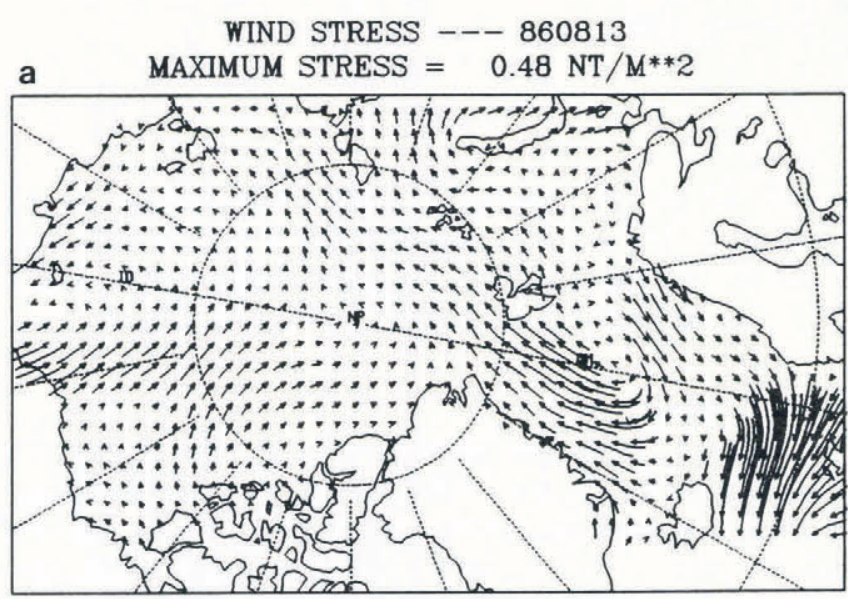

ICE VELOCITIES - - 860813

bAXIMUM VELOCITY $17.2 \mathrm{CM} / \mathrm{SEC}$

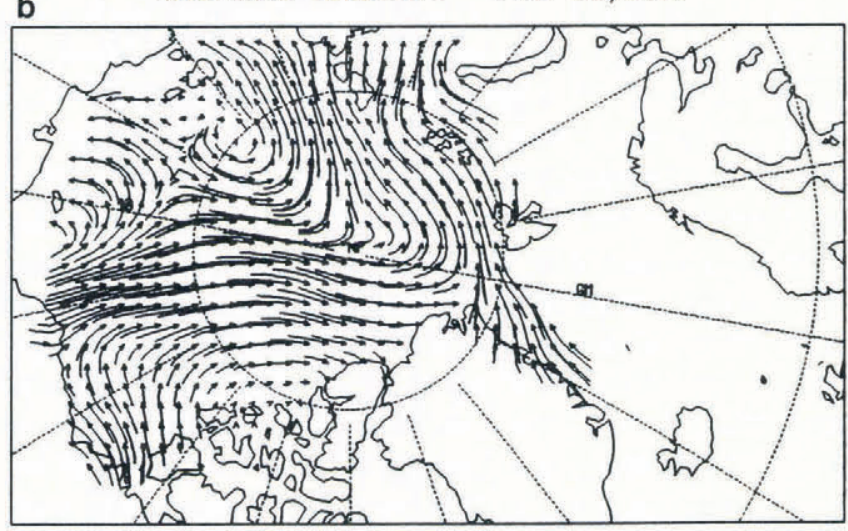

Fig. 10. The wind stress (a) and ice-drift motion (b) 13 August 1986.
WIND STRESS -- 860817

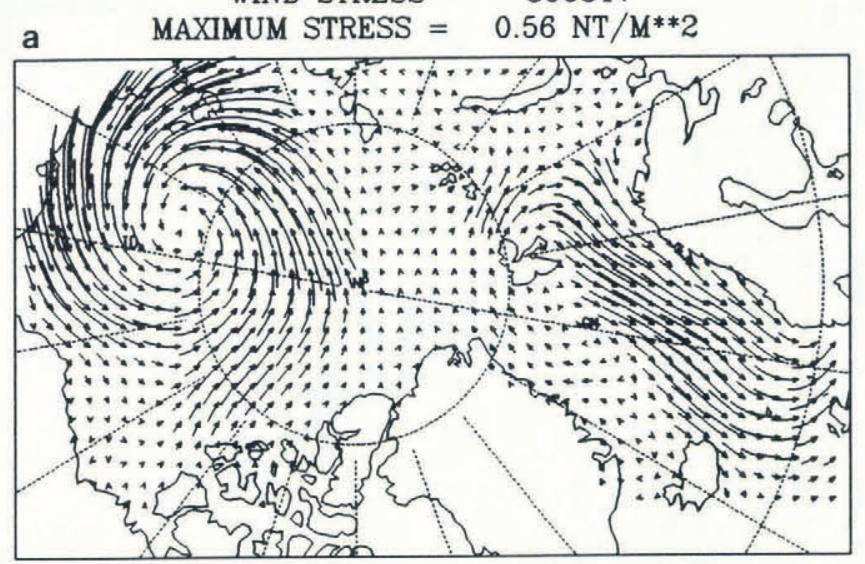

ICE VELOCITIES - - 860817

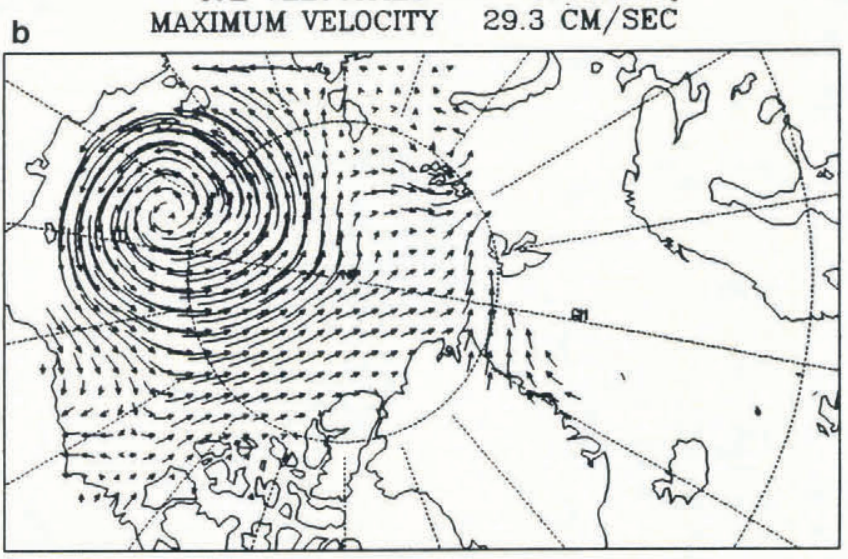

Fig. 11. The wind stress (a) and ice-drift motion (b) 17 August 1986.

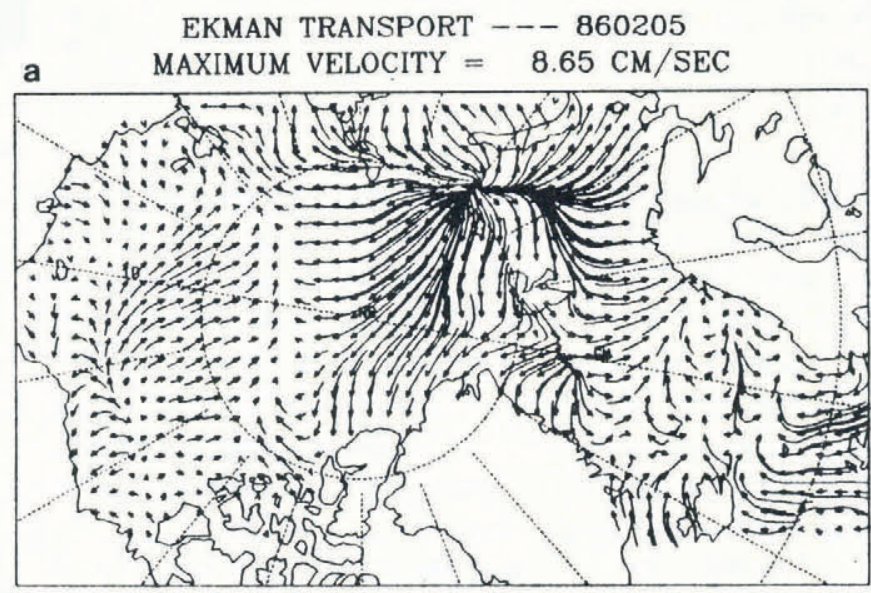

50 METER AVERAGE EKMAN TRANSPORT --- 860817 b

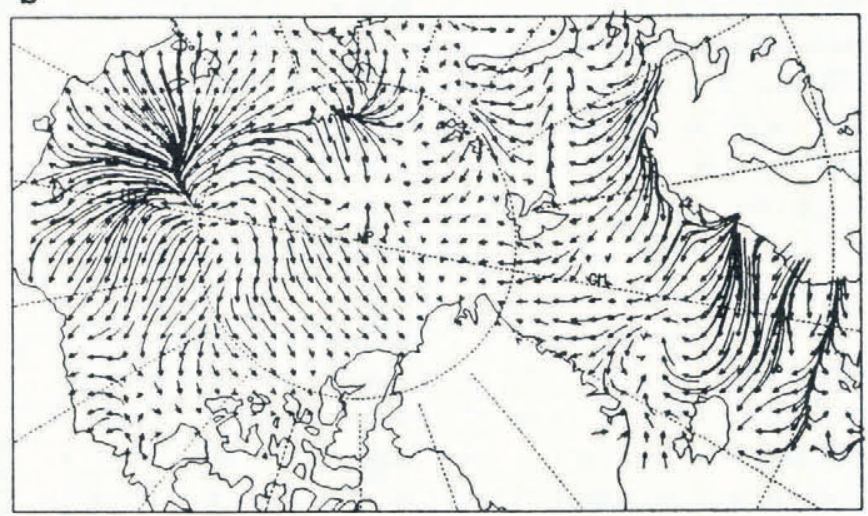

Fig. 12. The 1986 Ekman transports: (a) transport for 5 February, (b) transport for 17 August. 


\section{ROLE OF ICE COVER IN MOMENTUM TRANSFER}

To get a feeling for this role, we have simulated the winddriven barotropic currents with two kinds of forcing: the entire wind stress and the ice-water drag (under the ice). The results for September are presented in Figure 13. The maximum velocities for the wind-stress case are larger than the drag case by a factor of two (4.5 versus $1.9 \mathrm{~cm} \mathrm{~s}^{-1}$ ). The cyclonic gyres in the Beaufort Sea and the Norwegian Sea are about the same, but the two anticyclonic gyres, one near Spitsbergen and the other $90^{\circ}$ east on the same latitude, are stronger in the wind-stress case.

\section{CONCLUSIONS}

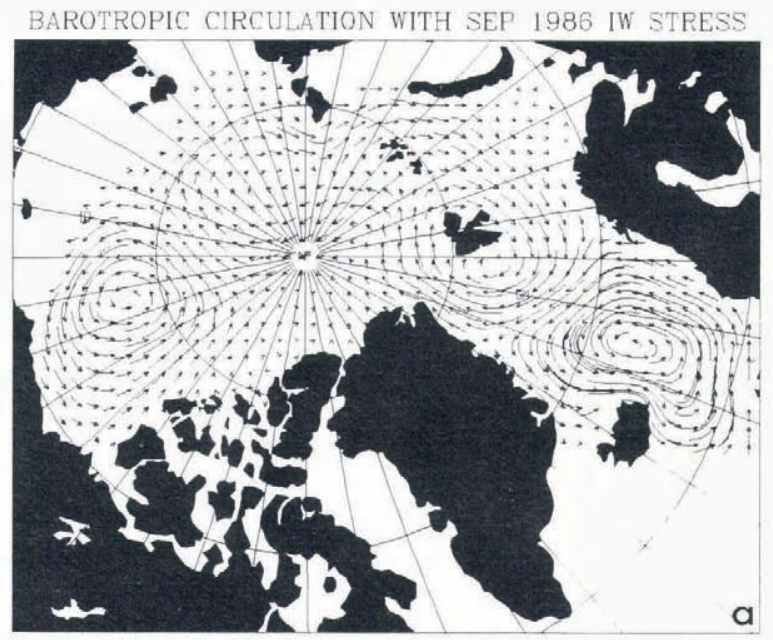

We have made a numerical study of the Arctic ice cover and upper ocean using a 3-D coupled ice-ocean model. The model incorporated a turbulent mixed-layer model, and was forced with daily GCM-derived $12 \mathrm{~h}$ atmospheric fluxes. In particular, we examined the momentum transfer and circulation response to the transient winds and heat fluxes, and made an initial study of the synoptic and seasonal variabilities of ice-drift motion, Ekman transport and barotropic currents.

Preliminary examination of the model results revealed no significant seasonal dependence of ice-drift response on the synoptic time scale, other than larger velocities with larger wind stresses. Daily maximum ice-drift velocities range from $20-40 \mathrm{~cm} \mathrm{~s}^{-1}$ in February and $15-30 \mathrm{~cm} \mathrm{~s}^{-1}$ in August. The corresponding mean monthly maximum drifts were 11 and $9 \mathrm{~cm} \mathrm{~s}^{-1}$, respectively. In contrast, the barotropic response of the ocean is very different in the winter than in the summer, with the ice cover playing a much more important role in winter. The drag associated with the geostrophic currents, however, plays a much bigger role in the summer because of the lighter atmospheric stresses.

The well-known reversal of the normally clockwise Beaufort Gyre to a cyclonic system in August takes place in a few days and lasts well into September. In February, this gyre varies between a large, clockwise system covering all the Canadian Basin to a small, tight gyre centered over the southern Beaufort Sea. There is no evidence of any reversal or even disappearance of the gyre in February.

The large divergence areas seen in the Ekman transport patterns are important for ice formation: in divergent areas the ice will thin or open up and refreezing will follow.

Follow-on studies will examine other months of 1986 , as well as other years of forcing. The model will be modified to employ a prognostic ocean model with twoway coupling of the baroclinic currents and the computed density changes, and to include detailed correlations between forcing, ice-drift motion and ocean currents.

\section{ACKNOWLEDGEMENTS}

The authors are greatly indebted to Ms Ruth Preller and Ms Shelley Riedlinger of NOARL for many helpful discussions concerning the Beaufort Gyre reversal and oceanic heat flux computations. Many thanks are also extended to the referees that helped improve the paper substantially. This work was funded by the Naval Oceanographic and Atmospheric Research Laboratory under Program Element 601153N. 


\section{REFERENCES}

Björk, G. 1989. A one-dimensional time-dependent model for the vertical stratification of the upper Arctic Ocean. 7. Phys. Oceanogr., 19, 52-67.

Clancy, R.M. and K.D. Pollak. 1983. A real-time synoptic ocean thermal analysis/forecast system. Prog. Oceanogr., 12, 383-424.

Creegan, A. 1976. A numerical investigation of the circulation in the Norwegian Sea. Tellus, 28(5), 451-459.

Hibler, W.D., III. 1979. A dynamic thermodynamic sea ice model. 7. Phys. Oceanogr., 9(4), 815-846.

Hibler, W.D., III, and K. Bryan. 1987. A diagnostic iceocean model. 7. Phys. Oceanogr., 17(7), 987-1015.

Lemke, P. 1987. A coupled one-dimensional sea ice-ocean model. 7. Geophys. Res., 92(C12), 13,164-13,172.

Levitus, S. 1982. Climatological atlas of the world ocean. NOAA Prof. Pap. 13.

McPhee, M.G. 1982. Sea ice drag laws and simple boundary layer concepts, including application to rapid melting. CRREL Rep. 82-4.

McPhee, M.G. 1990. Small-scale processes. In Smith, W.O., jr, ed. Polar oceanography. Part A. Physical science. San Diego, CA, Academic Press, 287-324.

Mellor, G.L. and L.H. Kantha. 1989. An ice-ocean coupled model. 7. Geophys. Res., 94(C8), 10,937-10,954.

Mellor, G.L. and T. Yamada. 1974. A hierarchy of turbulence closure models for planetary boundary layers. J. Atmos. Sci., 31, 1791-1806.
Olbers, D.J., M. Wenzel, and J. Willebrand. 1985. The inference of North Atlantic circulation patterns from climatological hydrographic data. Rev. Geophys., 23, 313316.

Peggion, G. 1988. A method for determining absolute velocities from hydrographic data. La Spezia, SACLANT Research Centre. (Report SR-114.)

Piacsek, S., R. Allard, and A. Warn-Varnas. In press. Studies of the Arctic ice cover and upper ocean with a coupled ice-ocean model. 7. Geophys. Res.

Preller, R.H. 1985. The NORDA/FNOC polar ice prediction system (PIPS)-Arctic: a technical description. NORDA Tech. Rep. 108.

Preller, R.H. and P.G. Posey. 1989. A numerical model simulation of a summer reversal of the Beaufort gyre. Geophys. Res. Lett., 16(1), 69-72.

Semtner, A.J., Fr. 1987. A numerical study of sea ice and ocean circulation in the Arctic. 7. Phys. Oceanogr., 17(8), 1077-1099.

Svensson, U. and A. Omstedt. 1990. A mathematical model of the ocean boundary layer under drifting melting ice. F. Phys. Oceanogr., 20(2), 161-171.

Walsh, J.E., W.D. Hibler, III, and B. Ross. 1985. Numerical simulation of Northern Hemisphere sea ice variability, 1951-1980. 7. Geophys. Res., 90(C3), 48474865 .

The accuracy of references in the text and in this list is the responsibility of the authors, to whom queries should be addressed. 